\title{
A Lower Hybrid Current Drive System for ITER
}

G.T. Hoang ${ }^{1}$, A. Bécoulet ${ }^{1}$, J. Jacquinot ${ }^{2}$, J.F. Artaud ${ }^{1}$, Y.S. Bae ${ }^{3}$, B. Beaumont ${ }^{4}$, J.H. Belo ${ }^{5}$, G. Berger-By ${ }^{1}$, João P.S. Bizarro ${ }^{5}$, P. Bonoli ${ }^{6}$, M.H. Cho ${ }^{7}$, J. Decker ${ }^{1}$, L. Delpech ${ }^{1}$, A. Ekedahl $^{1}$, J. Garcia ${ }^{1}$, G. Giruzzi ${ }^{1}$, M. Goniche ${ }^{1}$, C. Gormezano ${ }^{8}$, D. Guilhem ${ }^{1}$, J. Hillairet ${ }^{1}$, F. Imbeaux $^{1}$, F. Kazarian ${ }^{4}$, C. Kessel ${ }^{9}$, S.H. Kim ${ }^{10}$, J.G. Kwak ${ }^{11}$, J.H. Jeong ${ }^{7}$, J.B. Lister ${ }^{10}$, X. Litaudon $^{1}$, R. Magne ${ }^{1}$, S. Milora ${ }^{12}$, F. Mirizzi ${ }^{13}$, W. Namkung ${ }^{7}$, J.M. Noterdaeme ${ }^{14}$, S.I. Park ${ }^{7}$; R. Parker ${ }^{6}$, Y. Peysson ${ }^{1}$, D. Rasmussen ${ }^{15}$, P.K. Sharma ${ }^{16}$, M. Schneider ${ }^{1}$, E. Synakowski ${ }^{17}$, A. Tanga $^{4}$, A. Tuccillo ${ }^{13}$, Y. X. Wan ${ }^{18}$.

${ }^{1}$ CEA, IRFM, F-13108 St Paul-lez-Durance, France.

${ }^{2}$ Cabinet of High Commissioner for Atomic Energy, CEA, F-91191 Gif-sur-Yvette, France.

${ }^{3}$ National Fusion Research Institute, Gwahangno -113, Yuseong-gu, Daejeon 305-333, Korea ${ }^{4}$ ITER Organization, F-13108 St Paul-lez-Durance, France.

${ }^{5}$ Associação Euratom-IST, Instituto de Plasmas e Fusão Nuclear, Instituto Superior Técnico, 1049-001 Lisboa, Portugal.

${ }^{6}$ Plasma Science and Fusion Center, MIT, Cambridge MA 02139, USA.

${ }^{7}$ Pohang University of Science and Technology, San-31, Hyoja-dong, Nam-gu, Pohang 790784, Korea.

${ }^{8}$ Private address: 72, Avenue de Versailles 75016 Paris.

${ }^{9}$ Princeton Plasma Physics Laboratory, Princeton, NJ 08543, USA.

${ }^{10}$ Association EURATOM-Confédération Suisse, CRPP-EPFL, 1015 Lausanne, Switzerland.

${ }^{11}$ Korea Atomic Energy Research Institute, Yuseong, Daejeon 350-600, Republic of Korea.

${ }^{12}$ Oak Ridge National Laboratory, Oak Ridge, Tennessee 37831-6169, USA.

${ }^{13}$ Association EURATOM-ENEA sulla Fusione, Frascati, Italy.

${ }^{14}$ Max-Planck-Institut für Plasmaphysik, EURATOM-Assoziation, Garching, Germany.

${ }^{15}$ US ITER Project Office, ORLN, Oak Ridge, Tennessee 37831-6483- USA.

${ }^{16}$ Institute for Plasma Research, Bhat, Gandhinagar-382428, India.

${ }^{17}$ Lawrence Livermore National Laboratory, USA.

${ }^{18}$ Institute of Plasma Physics, Chinese Academy of Sciences, Hefei, Anhui, P. R. China.

Email contact of main author: tuong.hoang@cea.fr 


\begin{abstract}
A $20 \mathrm{MW} / 5 \mathrm{GHz}$ Lower Hybrid Current Drive (LHCD) system was initially due to be commissioned and used for the second mission of ITER, i.e. the $\mathrm{Q}=5$ steady state target. Though not part of currently planned procurement phase, it is now under consideration for an earlier delivery. In this paper, both physics and technology conceptual designs are reviewed. Furthermore, an appropriate work plan is also developed. This work plan for design, R\&D, procurement and installation of a 20MW LHCD system on ITER follows the ITER Scientific and Technical Advisory Committee (STAC) T13-05 task instructions. It gives more detail on the various scientific and technical implications of the system, without presuming on any work or procurement sharing amongst the possible ITER partners ${ }^{1}$. This document does not commit the Institutions or Domestic Agencies of the various authors in that respect.
\end{abstract}

PACS: 52.50.Sw, 52.55.Fa

${ }^{1}$ The LHCD system of ITER is not part of the initial cost sharing 


\section{Introduction}

Lower Hybrid Current Drive (LHCD) has been one of the four well proven heating and current drive(H\&CD) systems on tokamaks for years; the others being: Neutral Beam Injection (NBI), Ion Cyclotron Resonance Frequency (ICRF), and Electron Cyclotron Resonance Frequency (ECRF). It is the key element of all the present devices addressing the long pulse issues, as it exhibits the highest current drive efficiency in present devices, and is fundamental for their inductive flux saving needs. In particular, all superconducting tokamaks (EAST [1], HT-7 [2], KSTAR [3], SST1 [4], Tore Supra [5] and TRIAM-1M [6]) have or plan LHCD capability. Since the emergence of the close link between the current profile and the turbulent transport properties, a strong renewed interest was found for LHCD in Advanced Tokamak (AT) researches. LHCD is extensively exploited in a large number of experiments (Alcator C-Mod, FTU, HT-7, JET, JT-60U, Tore Supra and TRIAM-1M) and has proven to be very effective at a significant level of power in ITER relevant conditions. It is often instrumental in providing the required off-axis current drive for both AT researches towards steady-state regimes, as well as for intermediate so-called Hybrid mode [7]. Thus, in ITER, LHCD in combination with other H\&CD methods would be a key tool for these three tasks: i) to sustain AT steady-state plasmas; ii) to extend the plasmas duration in the intermediate socalled Hybrid mode operation; iii) to save volt-seconds in the current ramp-up phase, low beta;

In this paper, an LHCD system capable of fulfilling several important tasks on ITER is presented. Based on experimental results, several simulations of scenario using LHCD in combination with other heating schemes have been performed, including volt-second savings (up to $45 \mathrm{~Wb}$ ), sustaining Hybrid (up to $1000 \mathrm{~s}$ ) and steady state scenarios ( $\mathrm{Q} \sim 7$ at $\mathrm{I}_{\mathrm{p}}=8.5 \mathrm{MA}$ for 3000s). The main technical issues: klystron development, power supplies, launcher design and transmission lines are discussed. Most critical issues such as the frequency choice and the power coupling are presented in detail, including risk assessment aspects. Finally a work plan allowing the installation of $20 \mathrm{MW}, 5 \mathrm{GHz} /$ one antenna system in the "second phase" of ITER operation, i.e. in time for the Advanced Mode Operation $(\mathrm{Q}=5$, steady-state), at the horizon 2020-2025 is presented. 


\section{Physics issues}

\subsection{Current drive aspects}

LH waves have the attractive property of damping strongly, via electron Landau damping, on relatively fast tail electrons with $\mathrm{v}_{/ /} \geq(2.5-3) \times \mathrm{v}_{\mathrm{Te}}$, where $\mathrm{v}_{\mathrm{Te}}=\left(2 \mathrm{~T}_{\mathrm{e}} / \mathrm{m}_{\mathrm{e}}\right)^{1 / 2}$ is the electron thermal velocity. The relatively high phase velocity allows for driving current quite efficiently and also minimizes deleterious effects due to particle trapping [8]. This unique feature explains why LHCD has the best efficiency among non-inductive external current drive systems. In particular, it is well-suited for driving current where or when the electron temperature is lower, such as during the start up phase of ITER or for off-axis current profile control in the steady state and hybrid scenarios.

The choice of the parallel index of the launched waves, $\mathrm{N}_{/ /}$-peak $\left(\mathrm{N}_{/ / 0}\right)$, is a trade-off between the current drive efficiency, the wave accessibility and the location of power deposition, all of which depends upon the plasma conditions. While the ideal configuration would offer some flexibility on $\mathrm{N}_{/ / 0}$ in order to optimize and control LHCD, a launched spectrum at $\mathrm{N}_{/ / 0} \sim 2$ appears to be a good compromise for ITER. Indeed, recent numerical simulations regarding the LH wave propagation across the ITER H-mode pedestal, indicate that for $\mathrm{N}_{/ /}>1.8$ the accessibility condition allows the wave to be damped beyond the pedestal upper bound $\left(\mathrm{n}_{\mathrm{e}} \approx\right.$ $6 \times 10^{19} \mathrm{~m}^{-3}$ in the ITER scenario 4) (Fig 1). Figure 1 also shows the limits in the densitytemperature plane $\left(n_{e}, T_{e}\right)$ for propagating $L H$ waves. It can be seen that an LH wave with initial $\mathrm{N}_{/ / 0}=2$ can propagate undamped across strong pedestals $\left(\mathrm{n}_{\mathrm{e}} \leq 1 \mathrm{x} 10^{20} \mathrm{~m}^{-3}\right.$ and $\mathrm{T}_{\mathrm{e}} \leq 8$ $\mathrm{keV})$. Thus, typical ITER pedestal parameters of $\mathrm{n}_{\mathrm{e}}=0.6 \times 10^{20} \mathrm{~m}^{-3}$ and $\mathrm{T}_{\mathrm{e}} \leq 5 \mathrm{keV}$ are located well inside the propagating region for $\mathrm{N}_{/ / 0}=2$.

Propagation and absorption issues have been studied using various relevant ray tracing/3D Fokker Planck code packages such as CQL3D/GENRAY $[9,10]$ and C3PO/LUKE $[11,12]$. Benchmarking of these codes has been done regarding the application of LHCD to ITER relevant regimes [6,13] (LUKE was previously named DKE in Ref [7]). For example, simulations performed for the ITER scenario 4 [14], indicate that LH waves drive current in the outer half of the plasma; $\mathrm{r} / \mathrm{a} \cong 0.6-0.8$ at a density of $7.25 \times 10^{19} \mathrm{~m}^{-3}$. Figure 2 displays the wave propagation and the $\mathrm{LH}$ current profile computed with C3PO/LUKE, with $30 \mathrm{MW}$ 
of injected power at $5 \mathrm{GHz}$ and various launched $\mathrm{N}_{/ / /}$. Concerning the physics aspects, the $\mathrm{LH}$ antenna design should aim at (1) increasing the power directivity, typically above $70 \%$; (2) increasing the spectral flexibility without compromising the power directivity and the antenna performance; and (3) reducing the fraction of power launched in the high $\mathrm{N}_{/ /}$-part of the spectrum in order to minimise the electrostatic acceleration of thermal electrons in the vicinity of the antenna (hot spot formation).

\subsection{Hybrid mode and steady-state operations}

Off-axis LHCD has already been shown to be an effective tool for optimizing the current profile for access to AT operating modes in many devices, in particular JET [15] and JT-60U [16]. In the framework of the International Tokamak Physics Activities on the Steady-State Operation (ITPA-SSO), predictive ITER simulations have been performed using various code packages, including ASTRA, CRONOS, ONETWO, TSC/TRANSP, TOPICS. The main conclusion is that LHCD is the unique CD method providing the non-inductive current far off-axis at normalized radius $\mathrm{r} / \mathrm{a}=0.6-0.8$, necessary for sustaining both the Hybrid and steady-state plasmas. The simulations using CRONOS indicated that the duration of a Hybrid pulse sustained by 20MW of ICRF and 30MW of NBI could be extended from 400s to 1000s when adding $20 \mathrm{MW}$ of LHCD [17]. As shown in Fig. 3a, the central safety, $\mathrm{q}(0)$, is maintained above and close to the unity (one of the main features of the Hybrid mode) for 1000s thanks to the off-axis LH current located at $\mathrm{r} / \mathrm{a}=0.7$ (Fig. 3b), while without LHCD $\mathrm{q}(0)$ drops rapidly below 1 after 400s. Simulations in Ref [18] have also showed that operating long pulse Hybrid mode using EC current drive, LHCD and NBI is possible (Q > 5, pulse duration $>3000 \mathrm{~s}$ at $\left.\mathrm{I}_{\mathrm{P}}=9 \mathrm{MA}\right)$.

Recently, CRONOS simulations also showed that steady-state plasmas could be achieved when using LHCD combined with other H\&CD schemes. Steady-state plasma with $\mathrm{Q} \sim 7$, at $\mathrm{I}_{\mathrm{p}}=8.5 \mathrm{MA}$ and Greenwald fraction of 0.8 , can be sustained by $20 \mathrm{MW}$ of LHCD, $16.5 \mathrm{MW}$ of ICRF, and $\sim 6 \mathrm{MW}$ of NBI. Fully RF steady-state Q 7 plasmas lasting 3000s (non-inductive fraction $\sim 97 \%$, resistive loop voltage $\sim 2 \mathrm{mV}$ ) are also expected, using $21 \mathrm{MW}$ of ECRF power, $20 \mathrm{MW}$ of ICRF power and 12MW of LH power (Fig. 4) [19]. In this scenario, LHCD plays an essential role of providing the required off-axis current at $\mathrm{r} / \mathrm{a}=0.6-0.8$, while $\mathrm{EC}$ waves are used in current drive scheme to control the current profile for triggering and lock the Internal Transport Barrier position at $\mathrm{r} / \mathrm{a} \sim 0.5$. 


\subsection{Volt-second saving issue}

LHCD-assisted start-up reduces flux consumption during current ramp-up, resulting in a longer flat top or burn time. Efficient poloidal flux saving using LHCD has been experimentally demonstrated at a number of facilities, for example, ALCATOR-C, PBX-M, and PLT in USA; HT-7 in China; JT60-U and TRIAM-1M in Japan; FT, FT-U, Petula-B, Tore Supra and WEGA-Grenoble in Europe. Simulations of current ramp up phase of 100s assisted by 20MW of LHCD, for the designed scenario 2, have been performed using various codes, such as CRONOS [20] (transport and current diffusion suite of codes), free-boundary transport evolution codes DINA-CH\&CRONOS [21] and TSC [22]. The main finding is that a volt-second saving of up to $\sim 45 \mathrm{~Wb}$ could be achieved, though accompanied by a decrease of plasma inductance $\left(l_{i}\right)$. An example of DINA-CH\&CRONOS simulation of the ITER reference scenario 2 ramp-up assisted by LHCD is shown in Fig. 5. In this simulation, a scaling based transport model benchmarked on JET experiments was used [23]:anomalous electron and ion heat conductivity profiles have a fixed radial shape $\chi \propto 1+6 \rho_{\text {tor }}^{2}+80 \rho_{\text {tor }}^{20}$ and are normalized to the IPB98(y,2) H-mode scaling with a correction factor 0.5 in order to mimic L-mode confinement.

As shown in Figure 5, an early application of 20MW LHCD during the plasma current rampup phase of the ITER reference scenario 2 is effective to reduce the flux consumption. Note that the saved flux of $43 \mathrm{~Wb}$ is equivalent to about 500sec of additional burn duration. In addition, the internal inductance drops from 1.05 to 0.71 , which is beneficial for the vertical stability through the poloidal field (PF) coil currents and remains compatible with the with the constraints of the present PF coil system design. A range of slightly reversed to flat target qprofile shapes can be achieved, as needed to operate ITER in advanced scenarios, as well as avoiding the onset of sawteeth during the ramp-up. Full scenario 2 simulations using the code TSC [24] indicate that the V-s saving is mainly due to the resistive part (38 Wb / $45 \mathrm{~Wb}$ with 20MW of LHCD power) and this is preserved to the end of burn. Extensive CRONOS simulations - by varying $\mathrm{N}_{/ /}, \mathrm{n}_{\mathrm{e}}, \mathrm{LH}$ power waveform, etc - indicate that applying $20 \mathrm{MW}$ of LHCD in the early current ramp-up phase could save $45 \mathrm{~Wb}$; and a decrease of $l_{i}$ with respect to the ohmic value, $\left|\Delta l_{i}\right|<0.3$ is expected (Fig. 6). The reduction of $l_{i}$ should impact the PF system (increasing the currents); in particular, it should affect the PF6 coil capacity. However, 
it is worth noting that the PF capacity issue is related to all the H/CD techniques used for voltsecond saving, L-H transition, and ITB formation (e.g., reversal magnetic shear scenario); this is due to a large change of the plasma profiles which make the shape evolution deviate from the reference scenario. This critical issue needs to be studied experimentally in the existing devices. More integrated simulations taking into account realistic transport models (heat, particle, impurity) benchmarked on a large number of experiments are also required.

\subsection{Other possible issues}

An intriguing application of far off-axis LHCD is the modification of the current density in the pedestal so as to affect the edge stability and hence the ELM behaviour. This aspect could be further modelled and/or investigated in existing devices if needed, though relevant pedestal conditions would be difficult to reproduce. From the recent Alcator C-Mod experiments, an interesting effect of LHCD on the pedestal of H-mode discharges has been reported in [25]. In these experiments, the density pump-out effect has been observed when the waves were marginally accessible to the edge.

The use of LHCD for breakdown and discharge initiation has been performed successfully in the past [26], although reproducibility has generally been difficult in other tokamaks. Further input on this topic from existing facilities with LHCD capability would be useful.

\section{Technology conceptual design}

\subsection{Klystrons}

Fusion research has triggered the development of several klystrons in the required frequency range, most notably at 3.7, 4.6 and $5 \mathrm{GHz}$. The design target and achieved performance of these klystrons are summarized in Table 1. No significant R\&D is required on the power sources, since these klystrons are either in the final stage of development $(5 \mathrm{GHz})$ or already produced in series (3.7 GHz [27]) (Fig. 7). The existing CW/4.6GHz tube, presently used in Alcator C-Mod, is able to provide $250 \mathrm{~kW}$ which is not high enough regarding the ITER LH system specification. The $3.7 \mathrm{GHz}$ tube has demonstrated good reliability in JET and Tore Supra for more than 20 years. The $500 \mathrm{~kW}$ tubes are used on Tore Supra to sustain long pulse 
operation (plasma lasting up to 6 minutes). At present, the $\mathrm{CW} 5 \mathrm{GHz}$ klystron is not yet validated at its required specification $(500 \mathrm{~kW} / \mathrm{CW} / \mathrm{VSWR}=1.4)$. The validation of this prototype could be reached within 1-2 years.

Table 1: CW klystron development for Fusion Devices

\begin{tabular}{|l|l|l|l|}
\hline Klystron & $\begin{array}{l}\text { Design } \\
\text { Target }\end{array}$ & $\begin{array}{l}\text { Achieved Performance of } \\
\text { Prototypes }\end{array}$ & Comments \\
\hline $\begin{array}{l}5 \mathrm{GHz} \\
\text { (Toshiba) }\end{array}$ & $\begin{array}{l}500 \mathrm{~kW} / \mathrm{CW} \\
\text { VSWR } 1.4\end{array}$ & $\begin{array}{l}303 \mathrm{~kW} / \mathrm{CW}(\mathrm{VSWR}=1) \\
508 \mathrm{~kW} / 0.5 \mathrm{~s}(\mathrm{VSWR}=1)\end{array}$ & $\begin{array}{l}\text { Ongoing } \\
\text { development For } \\
\text { KSTAR }\end{array}$ \\
\hline $\begin{array}{l}4.6 \mathrm{GHz} \\
(\mathrm{CPI})\end{array}$ & $250 \mathrm{KW} / \mathrm{CW}$ & Used in Alcator C-Mod & $\begin{array}{l}\text { Ongoing production } \\
\text { for EAST }\end{array}$ \\
\hline $\begin{array}{l}3.7 \mathrm{GHz} \\
(\mathrm{TED})\end{array}$ & $700 \mathrm{~kW} / \mathrm{CW}$ & $\begin{array}{l}767 \mathrm{~kW} / \mathrm{CW}(\mathrm{VSWR}=1) \\
670 \mathrm{~kW} / \mathrm{CW}(\mathrm{VSWR}=1.4)\end{array}$ & $\begin{array}{l}\text { Ongoing production } \\
\text { in series for Tore } \\
\text { Supra }\end{array}$ \\
\hline
\end{tabular}

For both $5 \mathrm{GHz}$ and $3.7 \mathrm{GHz}$ klystrons (gain of $48 \mathrm{~dB}$ and $50 \mathrm{~dB}$ for respectively $5 \mathrm{GHz}$ and 3.7 $\mathrm{GHz}$ tubes), an input RF power less than $10 \mathrm{~W}$ is required, which is easily achievable from a solid state amplifier. The RF output is made through two $\mathrm{BeO}$ windows, thus a recombiner is required to provide a single output. It is worth noting that some $R \& D$ of the recombiner is required for the $5 \mathrm{GHz}$ system.

For the $3.7 \mathrm{GHz}$ system, there is no $\mathrm{R} \& \mathrm{D}$ requirement since a recombiner operating at $3.7 \mathrm{GHz}$ already exists and has been validated for up to $750 \mathrm{~kW}$ to provide a single output with the standard waveguide WR 284.

\subsection{Launcher}

Several LH antenna concepts have been used in the past or present devices: i) classical grill (CG) with independently fed waveguides and with RF windows located near the plasma (Alcator C-Mod, FTU, KSTAR, PLT, SST1, TRIAM-1M); ii) Multijunction (JET, Tore Supra, JT60, TdV) and more recently Passive Active Multijunction (PAM); iii) quasi optical grill; iv) Slit waveguides array. From these studies, the actively cooled PAM launcher is found, despite having a somewhat lower directivity when compared to a fully active grill, to 
be the best concept for ITER. It satisfies simultaneously these three conditions: i) good coupling properties near the cut-off density; ii) capability to operate in steady-state; iii) simplicity inherent to a low number of components and control actuators.

The conceptual design of the $5 \mathrm{GHz}$ launcher was previously studied in Ref [28] and Ref [29] (Fig. 8a). This includes all the components of the transmission line (mode converters, tapers, hybrid junctions, windows). The fabrication of a PAM becomes tricky when increasing the source frequency. However, the PAM design has the advantage to require wider waveguides than a conventional multijunction for a given $\mathrm{N}_{/ /}$value. Thus, taking into account these two opposite effects, it is not foreseen further difficulties for manufacturing a 5GHz PAM with respect to a $3.7 \mathrm{GHz}$ conventional multijunction launcher which has been realized successfully [30]. To this concern, it is worth noting that an actively cooled 3.7 GHz PAM launcher (Fig. $8 \mathrm{~b}$ ) is being installed at Tore Supra (experimental validation of this launcher is expected by the end 2009) [31], and a PAM launcher has been tested successfully at 8GHz in FTU [32]. A detailed design of PAM launcher operating at 3.7GHz for JET has also been proposed [33].

\subsection{Power supply}

It would require one High Voltage Power Supply (HVPS) capable of supplying the beam voltage to power four parallel klystrons, typically $80 \mathrm{kV} / 100 \mathrm{~A}$ (for $500 \mathrm{~kW}$ klystrons at $5 \mathrm{GHz}$ or for $700 \mathrm{~kW}$ klystrons at $3.7 \mathrm{GHz}$ ). This choice will imply a set of 12 HVPS for the complete 24 MW LH system, according to the ITER Detailed Design Document in 2001 (DDD-2001). This configuration allows providing a flexible LH system in term of availability of power. An HVPS can be a modular pulsed switching module (PSM) based Regulator High Voltage Power Supply (RHVPS) that does not need a crowbar protection owing to its low stored energy and fast switch-off capability. This type of HVPS has versatile controls on voltage rise time, programmability of HV pulses, etc. A conventional HVPS on the other hand is less efficient (efficiency of about 90\%) and needs additional crowbar system to limit arc fault energy. All other auxiliary power supplies needed for klystron operation would be of conventional type.

\subsection{Transmission lines}

The main transmission line for the LH system consists of the following four sections: 
- the cryostat section, running from the vacuum vessel closure plate to the cryostat closure plate,

- the first mode converter (MC) section, running from the cryostat wall to the circular transmission line,

- the circular transmission line section, running between the $\mathrm{MC}$ at the two ends,

- the second mode converter section, running from the circular transmission line section to the klystron.

\section{Critical issues}

\subsection{Frequency choice}

Five $\mathrm{GHz}$ is the frequency chosen in DDD-2001. The choice of source frequency is governed by two important physics issues. Firstly, the wave frequency must be sufficiently high to avoid cyclotron damping on plasma ions. In particular, fusion-born alpha particles can absorb the wave energy even at very high harmonics (up to 100). Previous study of LH-alpha interaction, for the ITER-FEAT scenarios at $\mathrm{Q}=5$ and 10 , indicated that $5 \mathrm{GHz}$ is a minimum frequency required to keep parasitic $\alpha$ absorption under $10 \%$ [34]. Since then, more accurate and consistent simulations have been performed. This simulation work has been done [35] using an orbit following Monte Carlo code (SPOT) to assess the effect of transport induced by toroidal field (TF) coil ripple and the effect of anomalous ion transport on the spatial profile of fast alpha-particles for the steady state ITER Scenario 4 and for the ELMy H-mode Scenario 2. The results of these simulations are summarized in Figure 9. For $3.7 \mathrm{GHz}$, the LH power parasitically damped to the alpha-particles was found to be $\sim 8 \%$, a value smaller than initially thought even when taking into account both anomalous alpha transport $\left(\mathrm{D}=1 \mathrm{~m}^{2} / \mathrm{s}\right)$ and diffusion induced by TF field ripple. The contribution of the latter to the alpha absorption is very weak $(\sim 0.01 \%)$. Furthermore, the maximum local alpha particle losses were found to be negligible (of the order of a few tens of $\mathrm{kW} / \mathrm{m}^{2}$ ). These results suggest that the use of a 3.7GHz source is also acceptable for ITER with respect to the alpha absorption issue.

High frequency is then also required to avoid parametric decay instabilities (PDI) of the LH pump wave at the highest density envisaged for current drive. PDI has been found in all LHCD experiments, where fast electron tail and CD effects disappear above a density threshold [36]. This threshold correspond to: $f_{0} / f_{\mathrm{LH}} \approx 2$, where $f_{0}$ is the source frequency and 
$f_{\mathrm{LH}}=f_{\mathrm{pi}} /\left[1+\left(f_{\mathrm{pe}} / f_{\mathrm{ce}}\right)^{2}\right]^{1 / 2}$. Obviously, working at $5 \mathrm{GHz}$ would give a great margin of operation. Note that the source frequency of $3.7 \mathrm{GHz}$ is also acceptable for all scenarios of interest. Indeed, the value of $f_{0} / f_{\mathrm{LH}}$ is estimated to be in the range of 3-3.5 for the baseline $\left(\mathrm{n}_{\mathrm{e}}\right.$ $\left.=1 \times 10^{20} \mathrm{~m}^{-3}\right)$ and AT $\left(\mathrm{n}_{\mathrm{e}}=0.7 \times 10^{20} \mathrm{~m}^{-3}\right)$ scenarios, when operating in D or D-T (50/50) plasmas. For the flat-top high density Hydrogen phase of ITER operation, in which LHCD is not expected to play a role, the PDI threshold was found to be marginal $\left(f_{0} / f_{\mathrm{LH}} \sim 2\right)$.

Coupling aspects also constrain the frequency choice: increasing the working frequency improves the power coupling capability. The 20MW ITER specification for a single equatorial port requires the capability for the antenna to operate at a power density of 33 $\mathrm{MW} / \mathrm{m}^{2}$. The present baseline system in DDD-2001 consists of four PAM antenna blocks in view of satisfying this specification, using the conservative calculations. Based on the design value of the Tore Supra 3.7GHz/PAM launcher (expected to operate reliably at the level of $25 \mathrm{MW} / \mathrm{m}^{2}$ ), the choice of the $3.7 \mathrm{GHz}$ fallback solution would mean a typical $25 \%$ reduction of the overall coupled power capability of the antenna. However, from the scaling based including short LH pulses $(<1 \mathrm{~s})$ on the 8GHz/PAM experimental results on FTU [32], higher power handling capability could be achieved for both $5 \mathrm{GHz}$ and $3.7 \mathrm{GHz}$ systems. This needs to be confirmed by Tore Supra experiments when operating in steady-state with its $3.7 \mathrm{GHz} /$ PAM launcher.

\subsection{Coupling issue}

LH power coupling is constrained by the density in front of the launcher and by the power density which depends on the working frequency. LHCD have been used in long pulse Lmode operation: i) on Tore Supra, $\mathrm{LH}$ waves $(\mathrm{f}=3.7 \mathrm{GHz})$ are routinely coupled with two multijunction antennae at multi-Mega-Watt levels on long duration discharges lasting up to 6 minutes [37] with low reflection coefficients $(\leq 5 \%)$ at power density of $13 \mathrm{MW} / \mathrm{m}^{2}$ (typically $20 \mathrm{MW} / \mathrm{m}^{2}$ in one-minute discharges); ii) extremely long discharges, sustained by LHCD, lasting several hours have been achieved in TRIAM-1M [38, 39]. Long distance coupling one of crucial issues for ITER - has been demonstrated in L-mode plasmas at JT60-U [40, 41] and Tore Supra [42]. More recently, success in remote coupling LH power in JET ELMy plasmas having ITER-like shape, with the antenna-plasma distance of $15 \mathrm{~cm}[43,44]$, removes 
major concerns on the possibility of using LH on ITER. A successful technique at JET consists in using a gas pipe to inject deuterium to control the edge density, as shown in Fig. 10.

LH coupling is also constrained by magnetic connexions between the LH launcher and plasma facing components. Poloidal density inhomogeneity is expected from $\mathbf{E} \times \mathbf{B}$ convection resulting from differential biasing of flux tubes passing nearby the ICRH antenna. Experimental results from JET and Tore Supra have showed a modification in the LH coupling when applying simultaneous ICRH, due to the magnetic connection between the antennae [45]. Solutions to this problem exist for ITER. Therefore, the choice of the LH antenna port in ITER, minimizing the interaction with the ICRH antennae, must be taken at the present stage.

\section{Tentative work plan}

Following the detailed studies conducted during the ITER design review process in 2007 , the first conclusions that can be drawn concerning the deployment of the ITER LHCD system are the following:

- The $20 \mathrm{MW} / 5 \mathrm{GHz} / \mathrm{CW}$ solution using one Passive Active Multijunction (PAM) launcher in ITER is technically confirmed and the cost estimate is $\sim 100 \mathrm{M} €(\sim 69 \mathrm{kIUA}$, compared to the FDR costing $61 \mathrm{kIUA})$. About 9 years are necessary between the decision point by stakeholders and the start of the commissioning phase on ITER.

- A two step approach, consisting of a "Day1" $5 \mathrm{MW} / 5 \mathrm{GHz} / \mathrm{CW}$ system powering one fourth of the final PAM, is possible. It would initially cost $\sim 40 \mathrm{M} €$ (28kIUA), and requires 7 years (Fig. 11). The initial cost includes several elements of the final system (e.g. half the high voltage power supply or all the transmission lines) as well as extra elements like a dedicated port plug. Completing the $5 \mathrm{MW}$ to the full $20 \mathrm{MW}$ system would cost an extra 65-70 M€ (45-50kIUA) and require additionally 5 years (assuming a test phase is performed on ITER with the Day1 system excluding any overlap).

In both cases, the LHCD system has to be included in the ITER design and work plan immediately, in particular to guarantee the necessary infrastructure for its final installation (buildings, port, cooling, pumping and dedicated gas injection valve for power coupling). Not taking these aspects into account at once would severely impact on the future feasibility and cost effectiveness. 
- A dedicated modelling effort is also necessary. It requires $\sim 2$ - 3 years. The initial DDD2001 design must be updated, that includes the :

- RF analysis (using for example ALOHA, FELICE, GRILL3D, HFSS, TOPLHA), regarding various issues such as the power density, coupling, directivity.

- $\mathrm{N}_{/ /}$spectrum flexibility should also be reviewed. The initial design in the document DDD-2001 is based on an $\mathrm{N}_{\| \text {peak }}=2 \pm 0.1$. Increasing the flexibility of varying $\mathrm{N}_{\| \text {peak }}$ will allow operating in various scenarios; for example, lower $\mathrm{N}_{\| \text {peak }}$ (typically 1.8) would be required for the low density and/or $T_{e}$ phases such as the current ramp-up phase for V-s saving.

- thermo-mechanical analysis, regarding various issues such as neutrons damping, disruptions, hallo, forces/torque.

These analyses must include the propagation and absorption aspects in various ITER scenarios.

In parallel, it should be necessary to initiate the design of a $3.7 \mathrm{GHz}$ PAM with respect to ITER environment, for the fallback solution. The detailed designs are already available for JET and Tore Supra.

- The required ITER specific $R \& D$ activity concentrates on three main topics:

- The $500 \mathrm{~kW} / 5 \mathrm{GHz}$ klystron unit itself. The present choice of the $5 \mathrm{GHz}$ frequency is motivated by the specification on the coupled power from a single port (20MW) and the minimisation of the power coupled to alpha particles during the high-beta burning phases. At present, the Toshiba prototype klystron has not yet been validated at $500 \mathrm{~kW} / \mathrm{CW}$ but the required level of confidence can be reached within about 2 years, provided a clear sign of interest from ITER is given. Note that the $700 \mathrm{~kW} / 3.7 \mathrm{GHz} / \mathrm{CW}$ back-up solution is fully available, with an acceptable compromise on the two aspects mentioned above.

- The transmission lines and RF windows. These RF elements must be adapted to ITER, in terms of minimisation of the number of transmission lines and development and tests of RF windows at $5 \mathrm{GHz}$ exposed to the ITER environment.

- The PAM front end. The material constituting the very front end of the ITER launcher must be specified together with ITER IO and then dedicated R\&D is needed to plug such a front end to a conventional PAM structure.

Choosing the $3.7 \mathrm{GHz}$ fallback solution would suppress the risk on the klystron and reduce the $R \& D$ effort in time (1-2 years). 
- The specific situation of a "non yet agreed" procurement package requires a supplementary dedicated negotiation time, presently estimated at about 1 year.

- With such considerations in mind and the present understanding of the various operation phases of ITER, three scenarios can be envisaged for the installation of the ITER LHCD system:

- Scenario 1: LHCD is installed and commissioned for the $Q=5$ steady-state phase of ITER, as presently planned in the DDD-2001.

- Scenario 2: LHCD is installed and commissioned for the first Deuterium-Tritium plasmas of ITER (H-mode or Hybrid mode, Q=10 targets).

- Scenario 3: LHCD is installed and commissioned for the Hydrogen phase of ITER.

A straightforward risk analysis clearly shows that Scenario 3 is already out of reach with the above mentioned assumptions. The "Day1" solution investigated during the ITER Design Review (one fourth of the final 20MW system) remains marginally accessible but is hardly attractive with regard to the Volt-second saving specifications, that require full LHCD power. Scenario 1 is obviously still accessible, with comfortable time margins, but does not solve any of the three issues motivating the present study. Finally, Scenario 2 (at full power) represents a good compromise that allows the initial DT phase of ITER to benefit from the highest Voltsecond saving and current profile shaping capability, thus significantly improving the $Q=10$ discharges in duration and quality through a proper ramp-up phase optimisation. Selecting this scenario gives the properly timed signal to the fusion community and to the related industrial partners to carry on with ITER-specific LHCD developments.

\section{Conclusion}

LHCD is a mature H\&CD system in a large number of fusion devices. As the main flux saving system, it has been present on all the long pulse tokamak plasmas, and thus holds the injected energy world record > 1GJ (early application of 20MW LHCD during the ITER ramp-up baseline scenario2 could save $45 \mathrm{~Wb}$ ). The LHCD experience in terms of $\mathrm{CW}$ operation is indisputable. Furthermore, it is now increasingly admitted that LH waves have a unique capability to drive the current efficiently far off-axis as required in ITER steady state scenarios (steady-state plasma, $\mathrm{Q} \sim 7$ at $\mathrm{I}_{\mathrm{p}}=8.5 \mathrm{MA}$ over $3000 \mathrm{~s}$, could be achieved with 20 MW of LHCD).

Several fusion research institutes are likely to be well adapted in terms of competences to participate in the elaboration of the ITER LHCD system. Most of them have been connected 
to the present document, but not exclusively. The present situation with industry is satisfactory on the klystron production side (several providers amongst several partners, though only Toshiba has initiated a development program of the $5 \mathrm{GHz}$ klystron at present), as well as on the antenna manufacturing side. This is due to the fact that LHCD developments for EAST, KSTAR, SST1 and Tore Supra are presently underway. As pointed out in the document, the fragility comes from the extreme specificity of (high frequency/long pulse) LHCD, that deserves a careful attention, as the magnetic fusion community is the only customer for most of the techniques in use. Several fusion devices around the world could also be used, if needed, for prototyping and testing of components (CW klystrons, transmission lines, RF windows, antenna modules ...).

The present situation with LHCD on ITER involves the installation of a 20MW / one antenna system in the "second phase" of ITER operation at the horizon 2020-2025. The LHCD fusion community, as well as the industry, is seriously concerned by such a long term objective that requires continuity. The necessary $\mathrm{R} \& \mathrm{D}$ activity, needed to adapt the present LHCD technology to the ITER environment, requires a long term effort and dedicated resources that will not be allocated satisfactorily in such a frame. If a decision is not taken rapidly, LHCD know-how will rapidly disappear from both the fusion laboratories and the industry. The subsequent revival of LHCD will then represent a very large effort from the community with the corresponding associated risks.

\section{Acknowledgements}

Part of this work, supported by the European Communities under the contract of Association between EURATOM and CEA, was carried out within the framework of the European Fusion Development Agreement. The views and opinions expressed herein do not necessarily reflect those of the European Commission.

This report was prepared as an account of work by or for the ITER Organization. The Members of the Organization are the People's Republic of China, the European Atomic Energy Community, the Republic of India, Japan, the Republic of Korea, the Russian Federation, and the United States of America. The views and opinions expressed herein do 
not necessarily reflect those of the Members or any agency thereof. Dissemination of the information in this paper is governed by the applicable terms of the ITER Joint Implementation Agreement. 


\section{Figure captions}

Figure 1: Accessibility and damping conditions for LH waves at frequency of $5 \mathrm{GHz}$; these calculations are performed with the ITER parameters $(B=4 T)$. This graph is obtained from simple expressions that are validated by extensive numerical simulation. The shaded area corresponds to plasma conditions - in the $\left(\mathrm{n}_{\mathrm{e}} ; \mathrm{T}_{\mathrm{e}}\right)$ plane - for which no LH wave can propagate because $\mathrm{N}_{/ / \mathrm{a}}>\mathrm{N}_{/ / \mathrm{d}}$. In the non-shaded area, it is possible to find a value of $\mathrm{N}_{/ /}$such that $\mathrm{N}_{/ / \mathrm{a}}<$ $\mathrm{N}_{/ /}<\mathrm{N}_{/ / \text {d }}$. An LH wave with such value of $\mathrm{N}_{/ /}$can propagate. Conversely, for a given value of $\mathrm{N} / /$, drawing the corresponding horizontal and vertical lines from the top and right axes gives the domain in the $\left(n_{e} ; T_{e}\right)$ plane for which the corresponding LH wave can propagate. This domain is the south-west region delimited by these lines. The point on the graph indicates the operation point $\left(\mathrm{n}_{\mathrm{e}}=0.6 \times 10^{20} \mathrm{~m}^{-3}\right.$ and $\left.\mathrm{T}_{\mathrm{e}}=5 \mathrm{keV}\right)$ discussed in the text.

Figure 2: LH deposition in the ITER scenario 4 computed with the package C3PO (fast raytracing code) and LUKE (3-D Fokker-Planck solver): (a) wave propagation for $\mathrm{N}_{/ /}=2$ launched at three poloidal positions. Thicker black lines correspond to sections of power deposition; (b) radial profile of the LH current for various launched $\mathrm{N}_{/ /}$with no electric field effect, perfomed with $30 \mathrm{MW}$ of injected power at $5 \mathrm{GHz}$. A launcher directivity of $87 \%$ has been assumed, corresponding to an absorbed power of $\sim 26 \mathrm{MW}$.

Figure 3: CRONOS simulation of ITER Hybrid plasma using transport model GLF23 based on first principle. A Hybrid mode is sustained over 1000s by 20MW of ICRF and 30MW of NBI and 20MW of LHCD: (a) Central safety factor; (b): Current profile at $t=1200$ s [17].

Figure 4: ITER Q 7 steady-state scenario using RF H\&CD only (21 MW of ECRF current drive, $20 \mathrm{MW}$ of central ICRF heating, and $12 \mathrm{MW}$ of LHCD), performed with CRONOS

a) Time traces of plasma current $(I p)$, central density $\left(n_{e}(0)\right)$, fusion gain $(Q)$,

b) The fractions of bootstrap current $\left(\mathrm{j}_{\mathrm{BS}}\right)$, non-inductive current $\left(\mathrm{j}_{\mathrm{NI}}\right)$, Greenwald $\left(\mathrm{f}_{\mathrm{G}}\right)$,

c) Radial profiles of ion/electron temperatures $\left(T_{i}, T_{e}\right)$, plasma density $\left(n_{e}\right)$, density of different current components (total $(j)$, bootstrap $\left(j_{B S}\right)$, ECCD current $\left(j_{E C}\right), L H$ current $\left(\mathrm{j}_{\mathrm{LH}}\right)[19]$.

Figure 5: Time traces of the ITER baseline current ramp-up assisted by 20MW of LHCD simulated by the simulator DINA-CH / CRONOS [21]: plasma current (Ip), poloidal beta $\left(\beta_{\mathrm{p}}\right)$, 
safety factors at the center $\left(\mathrm{q}_{0}\right)$, LH power $\left(\mathrm{P}_{\mathrm{LH}}\right)$, internal inductance $\left(l_{i}(3)\right)$ and poloidal flux at the plasma boundary (dashed red lines: ITER reference scenario 2).

Figure 6: a) Envelop illustrating the decrease of plasma inductance versus Volt-sec saving (envelop), computed with CRONOS. Dashed trajectories (a, b, c, d) correspond to various waveforms of LH power shown in Fig. $6 \mathrm{~b}$.

Figure 7: a) prototype of $5 \mathrm{GHz}$ tube; b) prototype of $3.7 \mathrm{GHz} ; 4.6 \mathrm{GHz}$ tubes in operation on Alcator C-Mod.

Figure 8: a) ITER 5GHz PAM Launcher in the document DDD-2001 [28]; b) ITER-like 3.7 GHz PAM is being installed at Tore Supra (approximately one fourth of the ITER launcher).

Figure 9: Parasitic LH power absorption by alpha particles, computed with an orbit following Monte Carlo code (SPOT), for two source frequencies (5GHz and 3.7GHz) [35].

Figure 10: Demonstration of long distance LH coupling at JET with gas (GIM6, during 6-9s) injection during the H-mode phase. The coupling is degraded over the whole launcher when no gas is injected (4-6s). Shown are as function of time: NBI and ICRH powers, coupled LHCD power, total gas flow and near gas flow from GIM6, the $\mathrm{D}_{\alpha}$ signal showing the ELM activity, the positions of the LCFS relative to the poloidal limiter (ROG) and the LH launcher relative to the poloidal limiter (LPOS), and the average reflection coefficient on the LH launcher [43].

Figure11: Tentative work plan allowing the installation of 20MW, $5 \mathrm{GHz} /$ one antenna system in the "second phase" of ITER operation. 


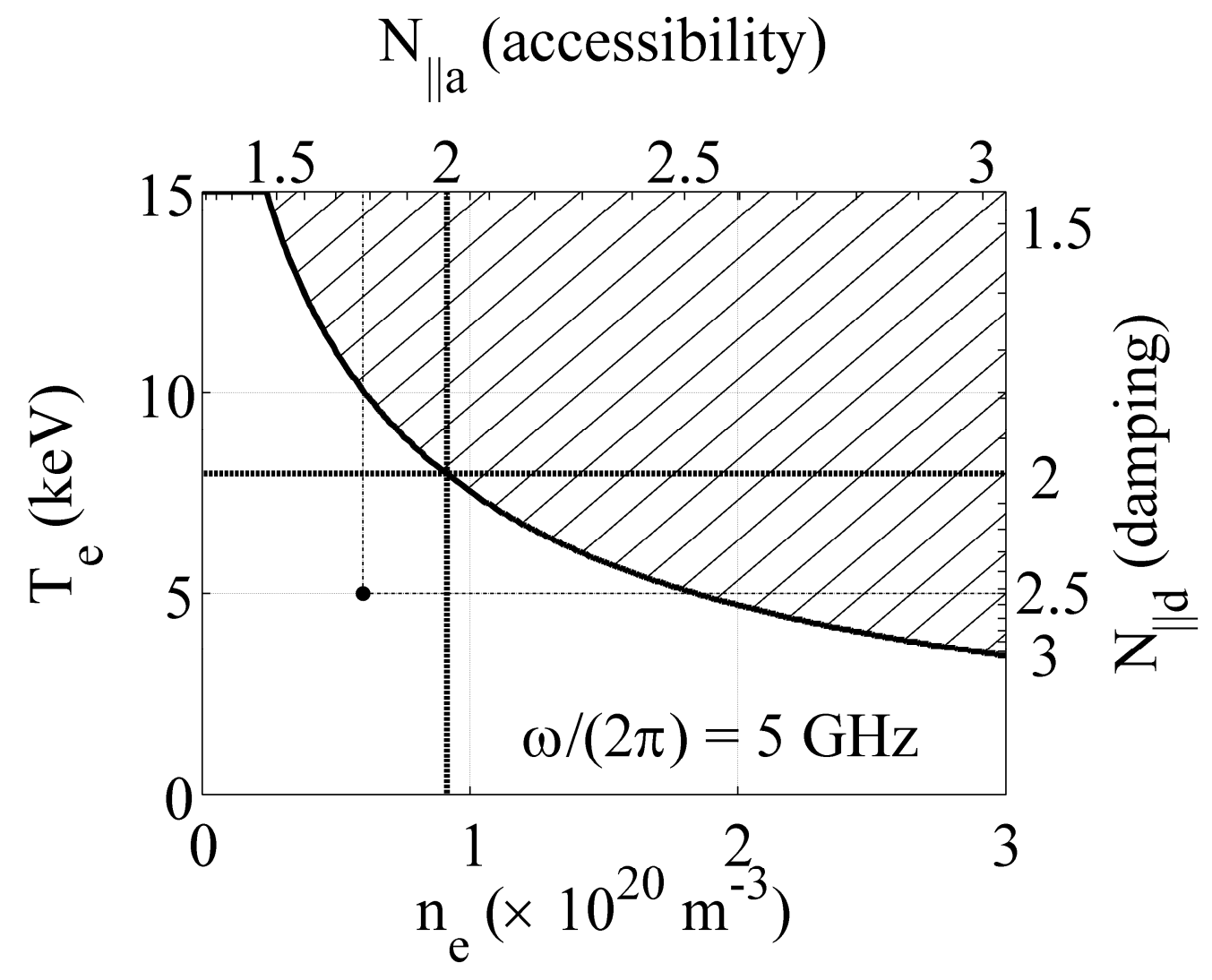

Figure 1 


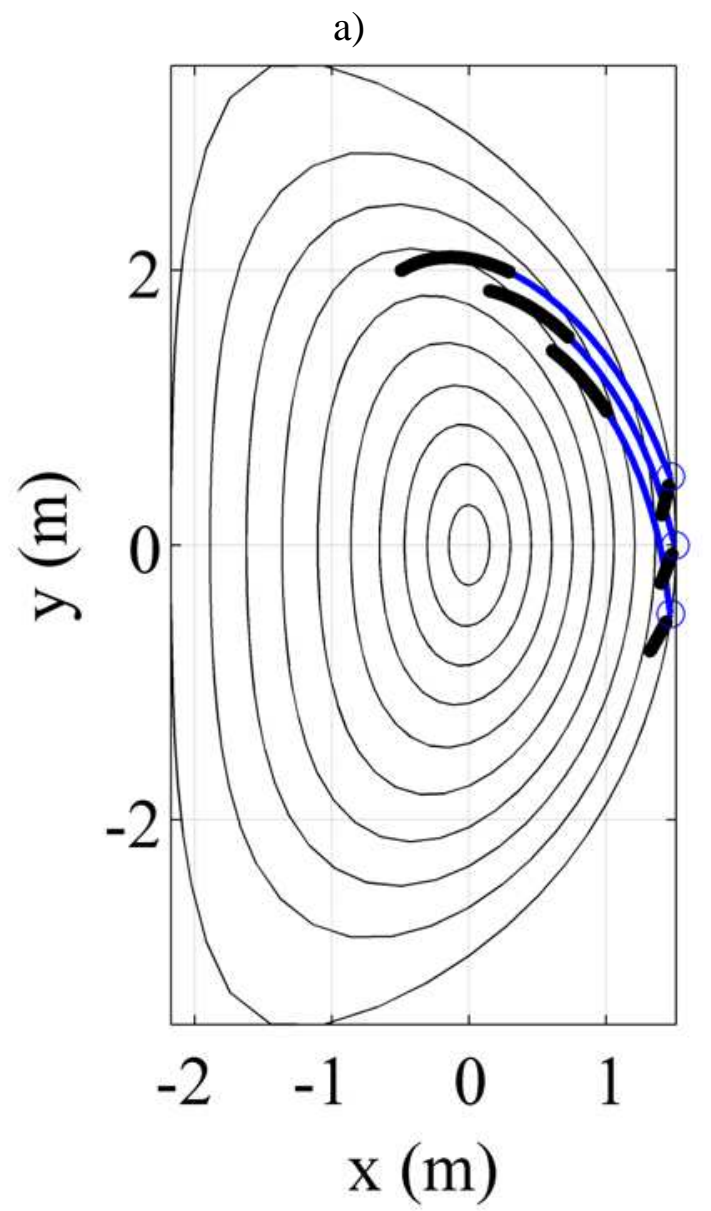

b)

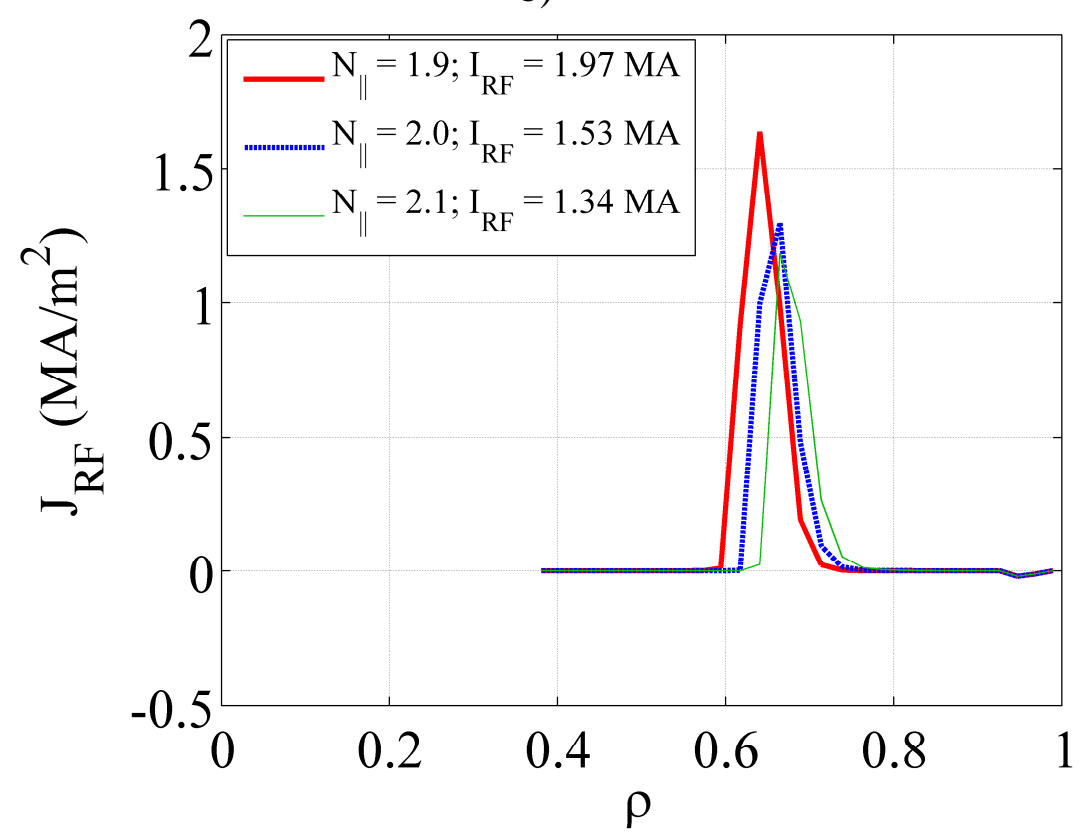

Figure 2 
a)

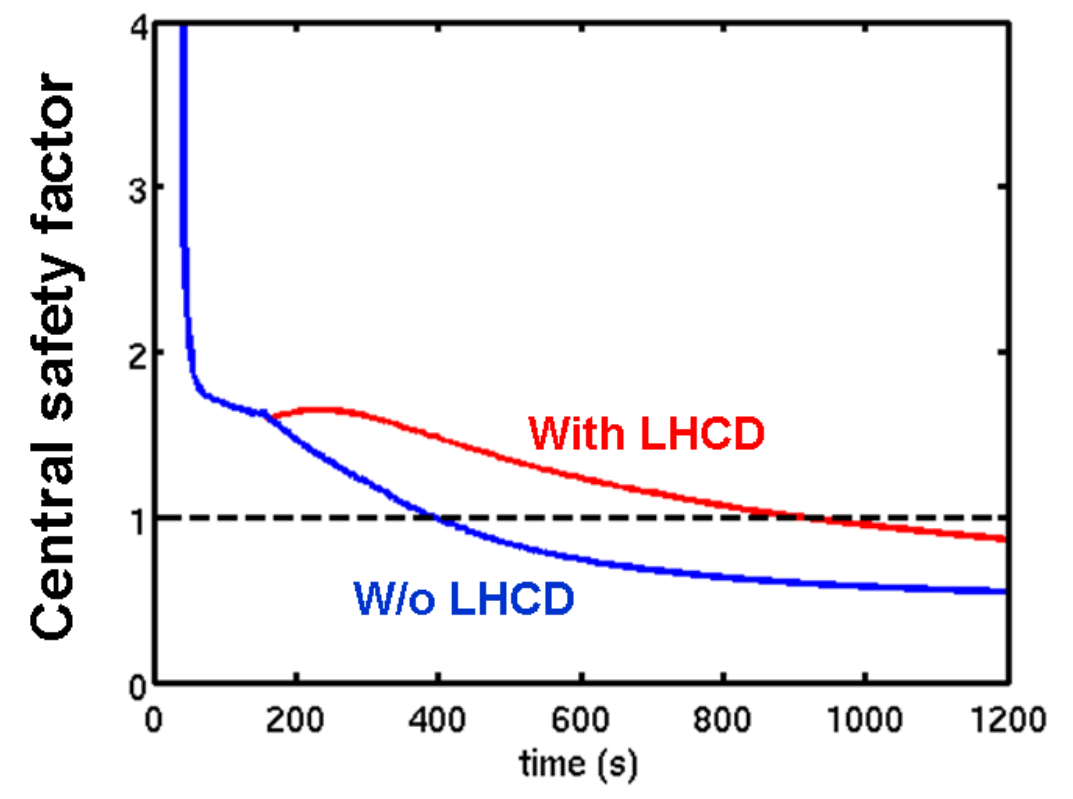

b)

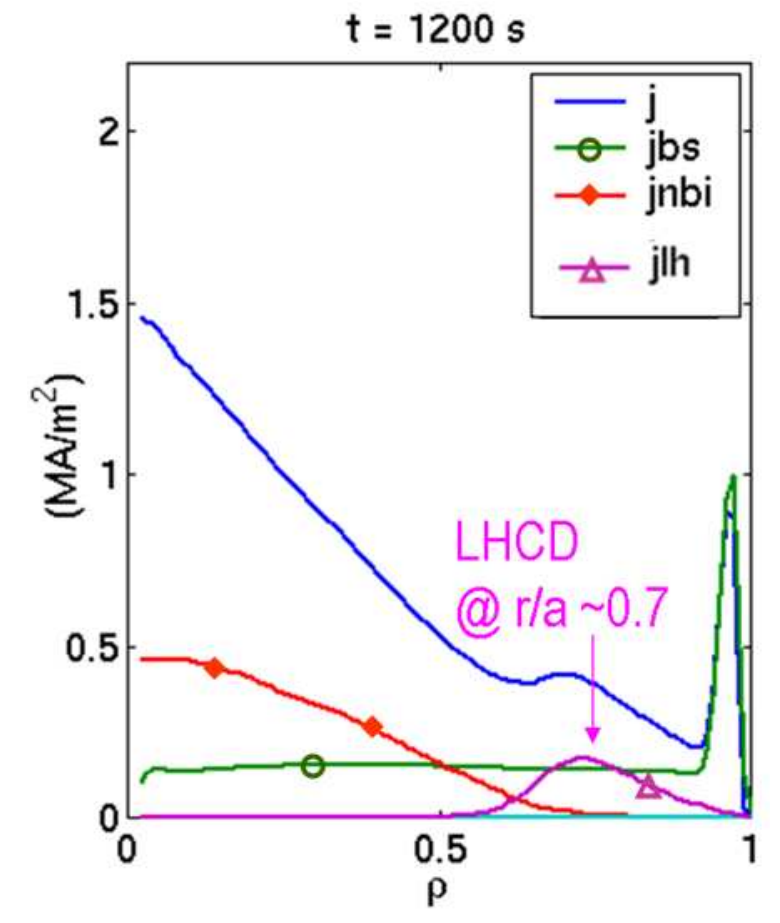

Figure 3 
a)

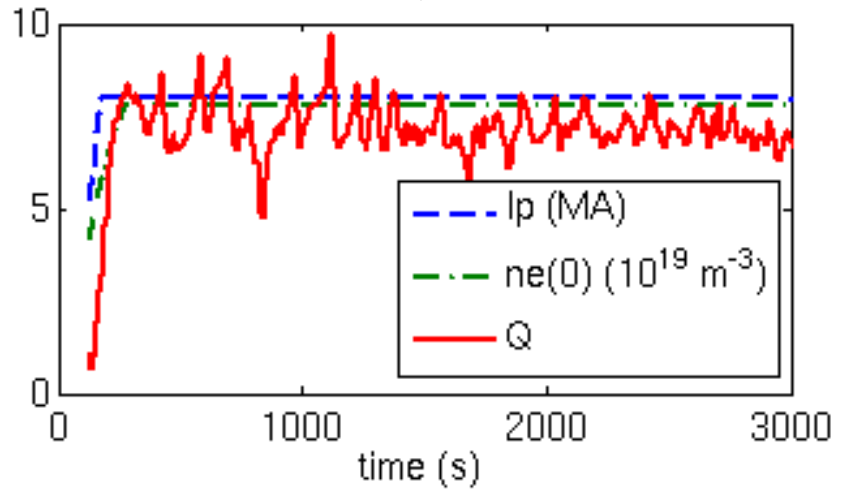

b)

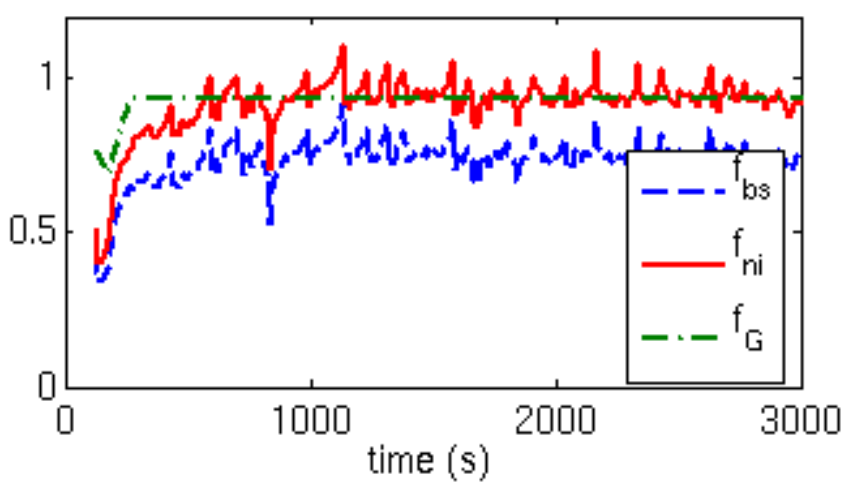

c)
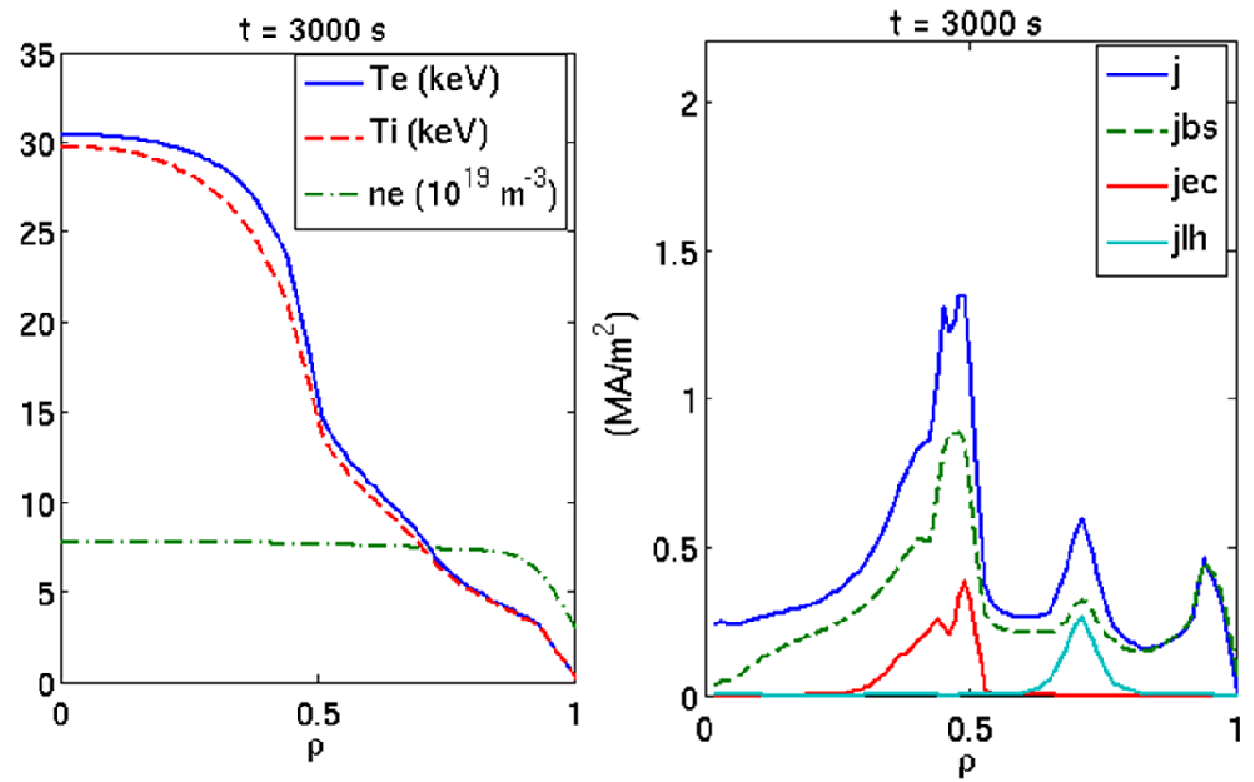

Figure 4 

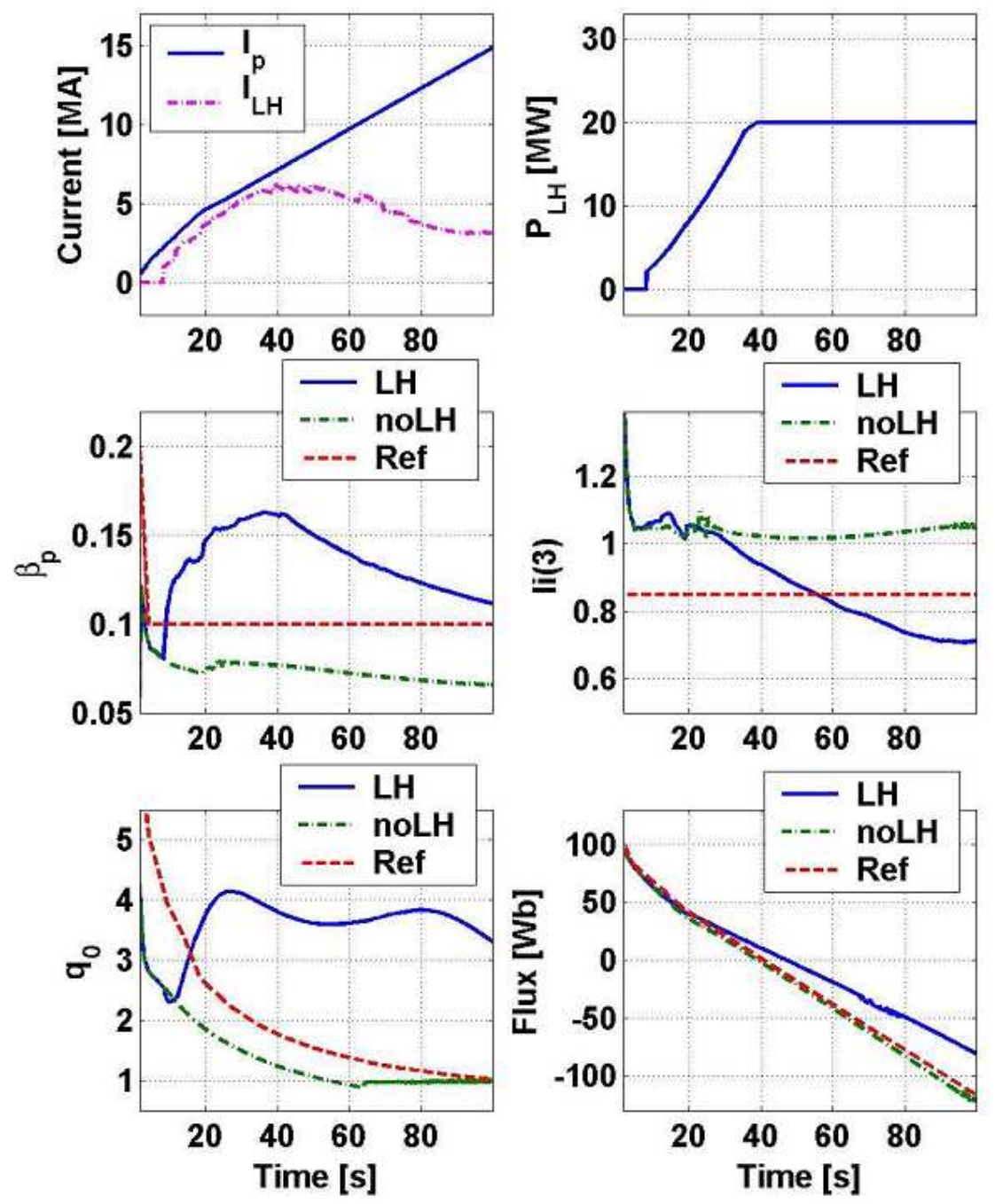

Figure 5 
a)

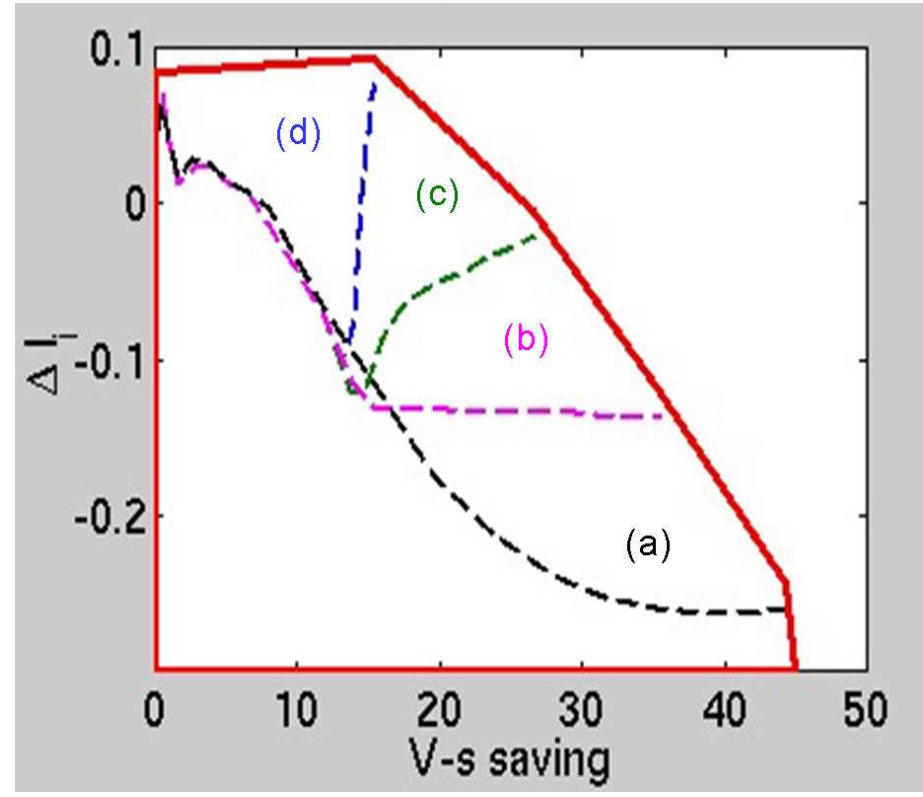

b)

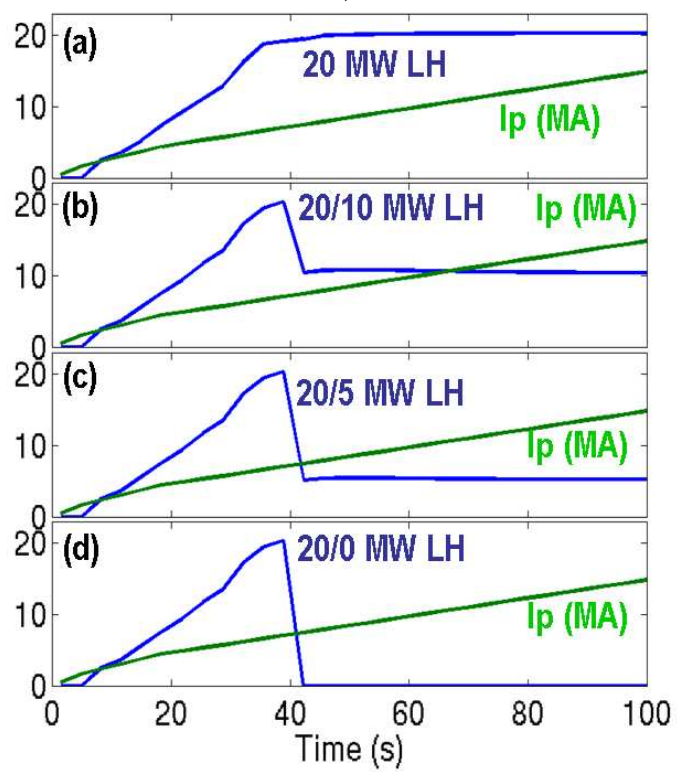

Figure 6 


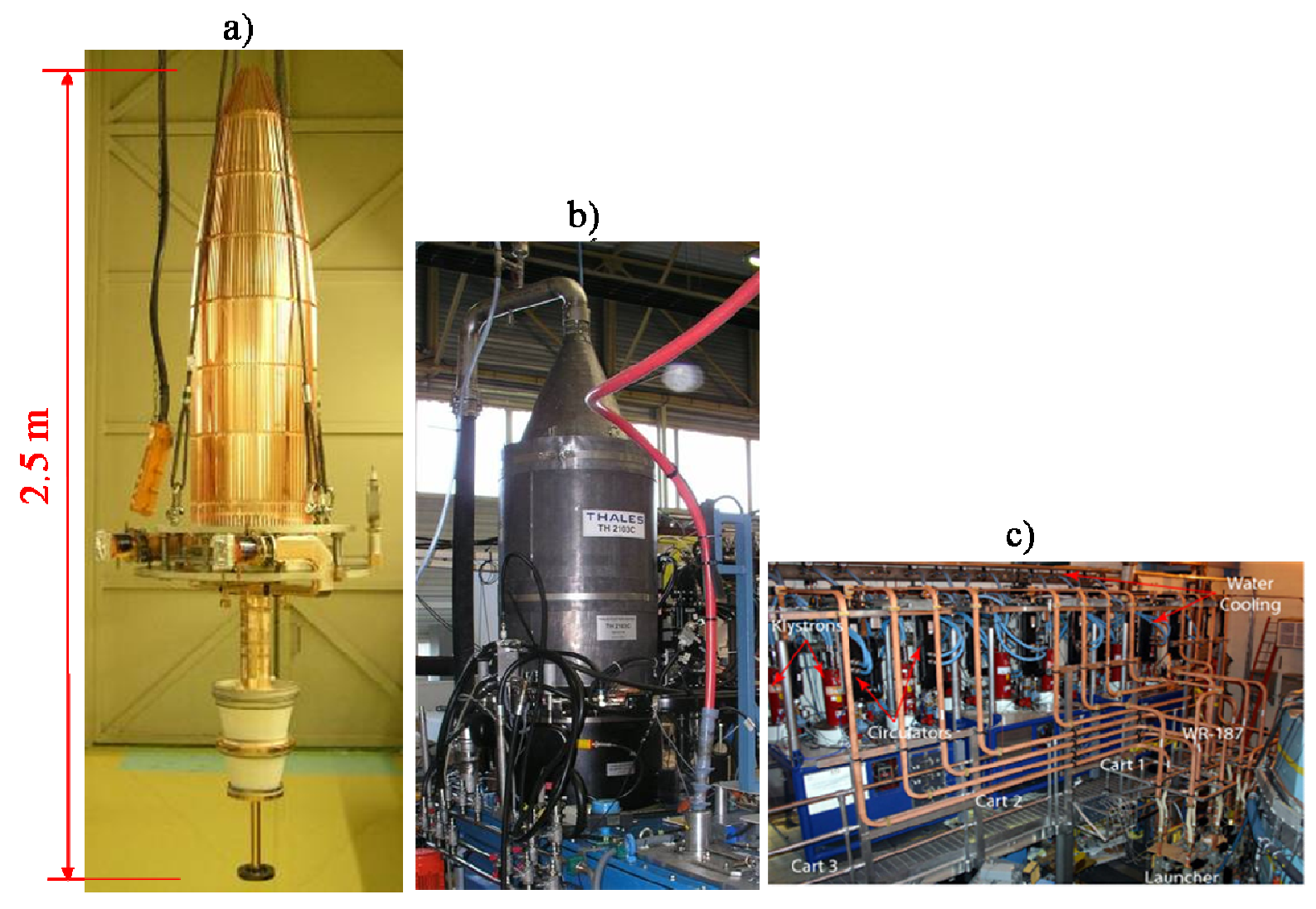

Figure 7 
a)

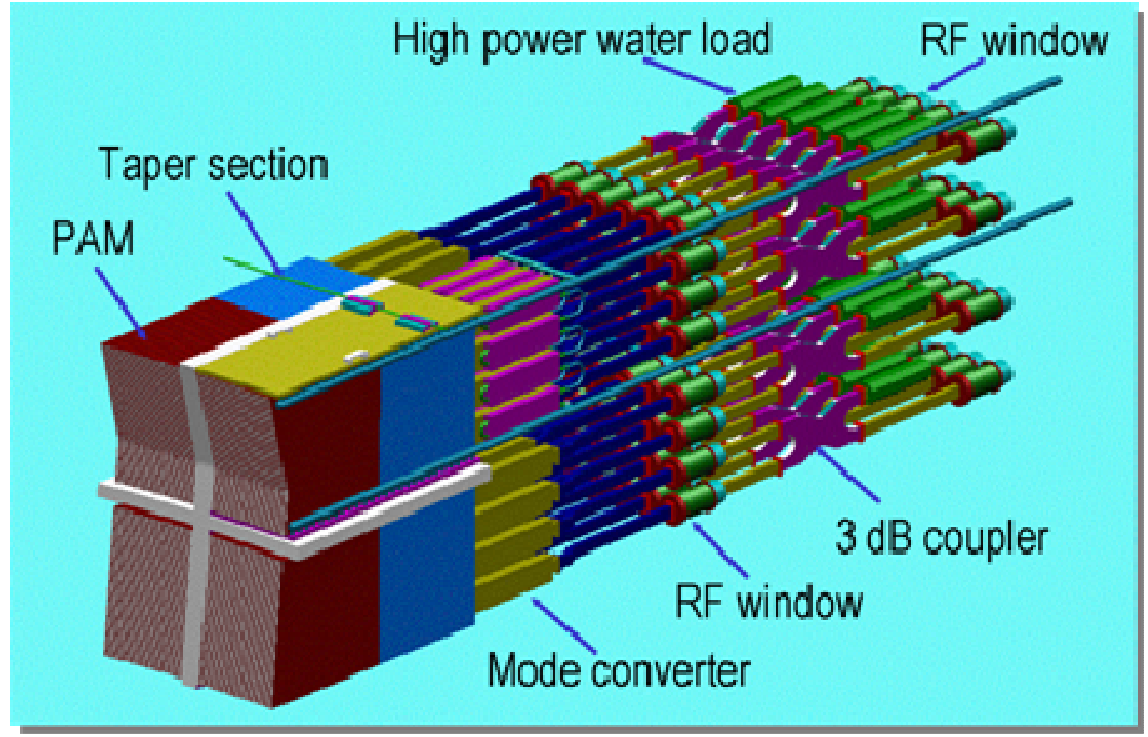

b)

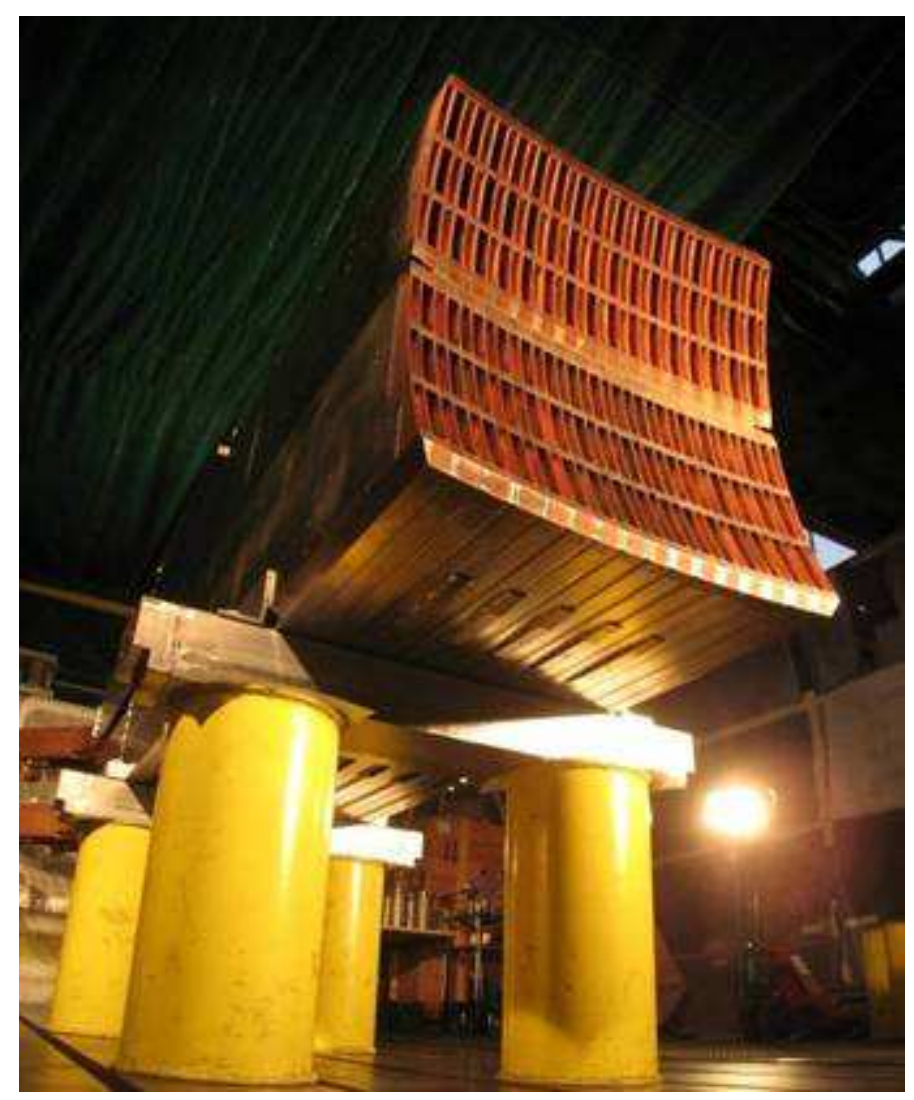

Figure 8 

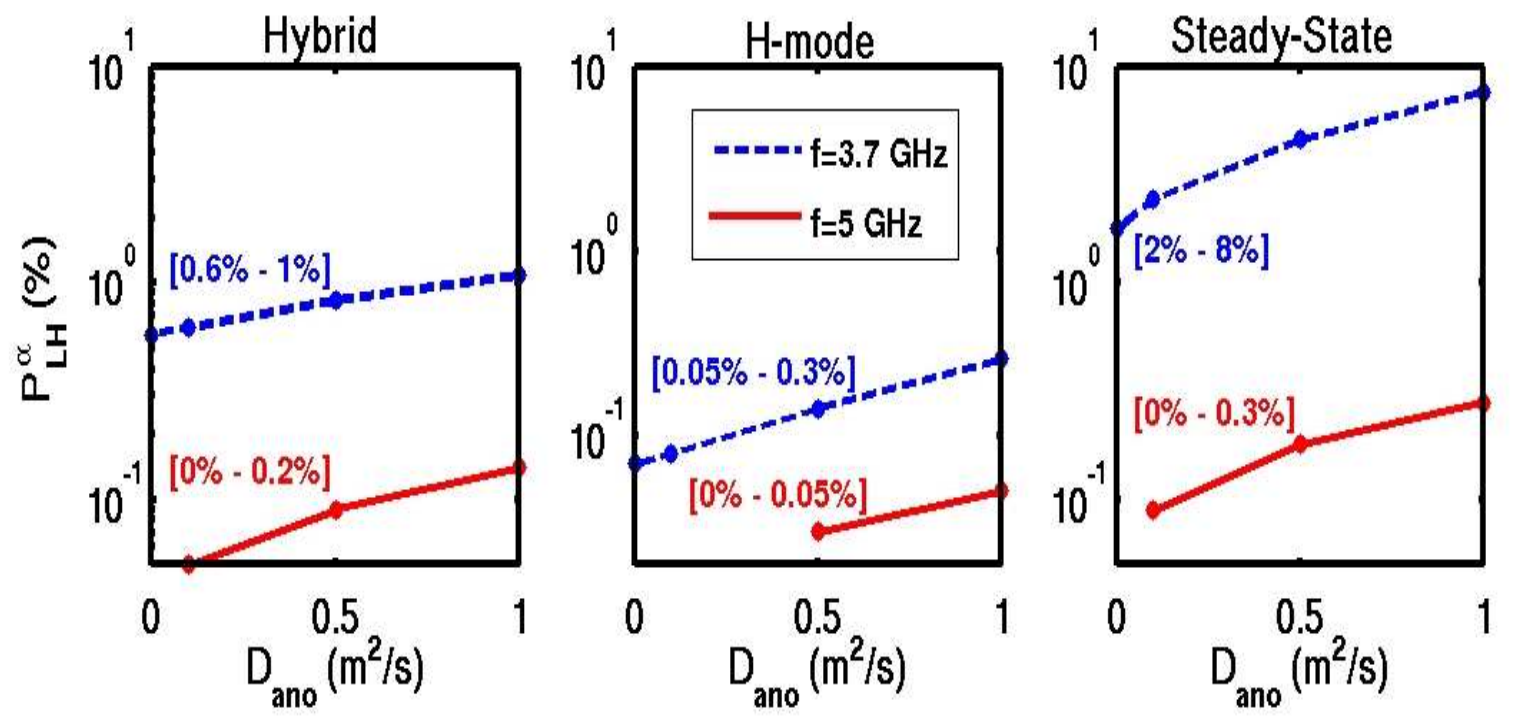

Figure 9 


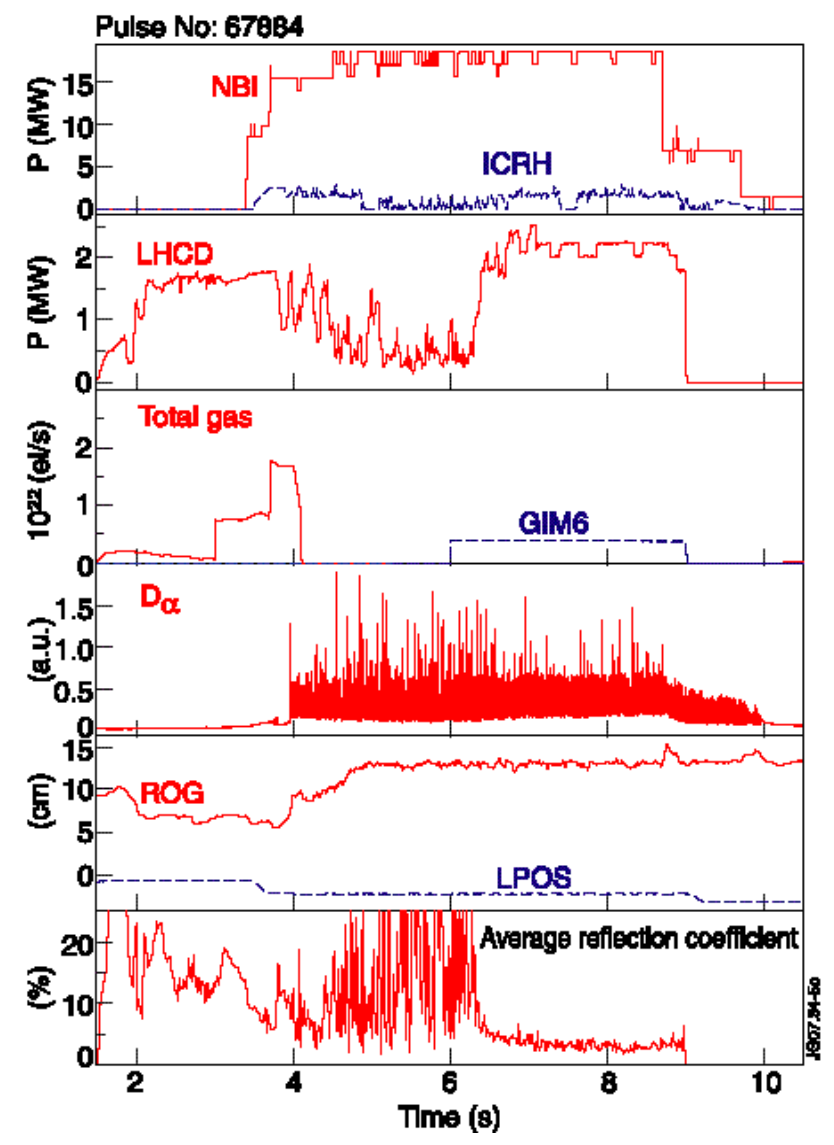

Figure 10 


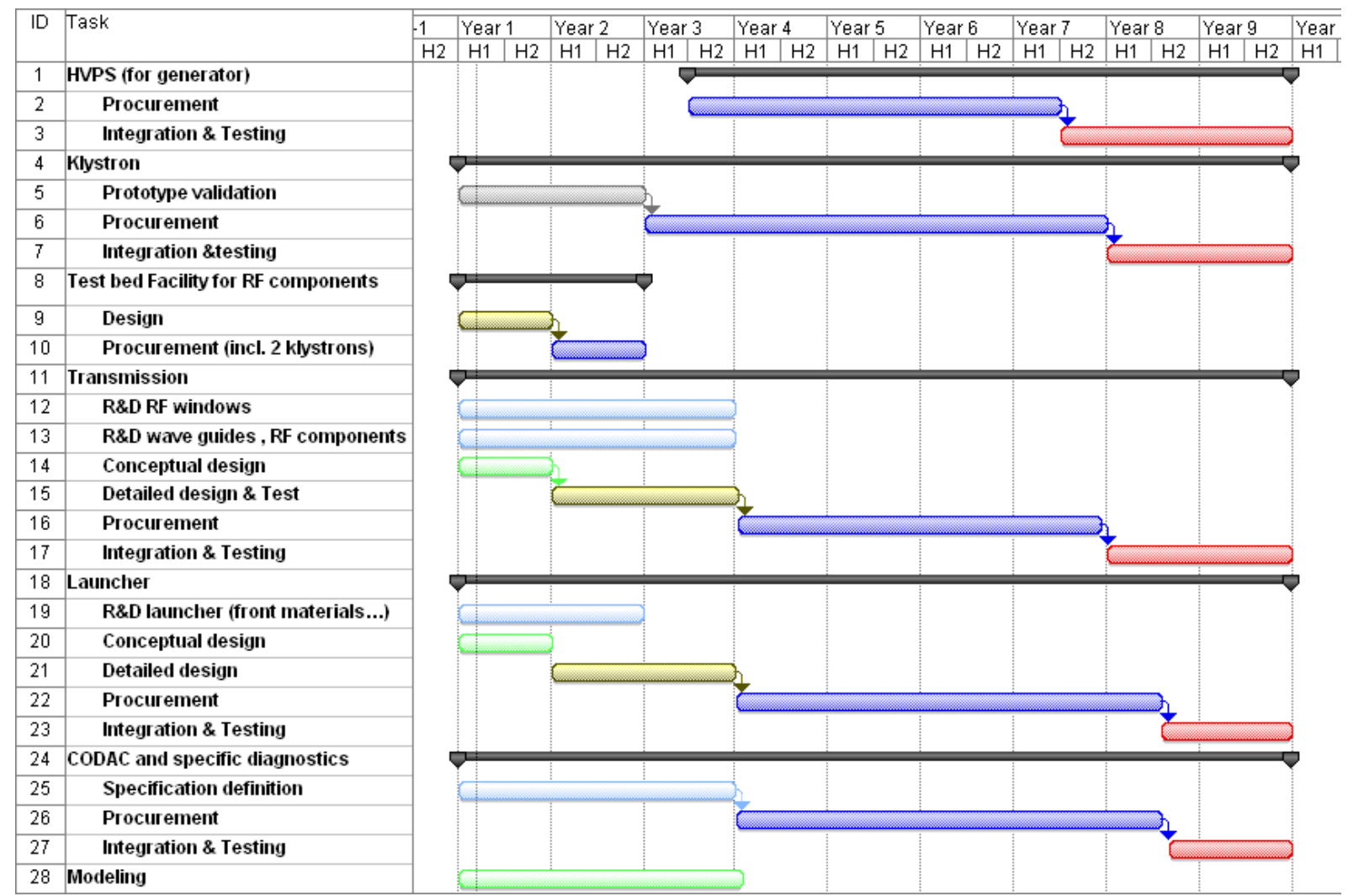

Figure 11 


\section{References}

[1] Y. Wan et al. in Fusion Energy 2006 (Proc. 21st Int. Conf. Chengdu, 2006) (Vienna: IAEA) CD-ROM file OV/1-1 and

http://www-naweb.iaea.org/napc/physics/FEC/FEC2006/html/index.htm

[2] Y. Wan et al. Nucl. Fusion, 40 (2000) 1057

[3] G. S. Lee et al. Nucl. Fusion 41 (2001) 1515

[4] D. Bora et al. Fusion Eng. Design Vol. 56-57 (2001) 575

[5] B. Beaumont et al. Fusion Eng. Design Vol. 56-57 (2001) 667

[6] S. Itoh et al., in Plasma Physics and Controlled Nuclear Fusion Research 1990 (Proc. 13th Int. Conf. Washington DC, 1990), Vol. 1, p. 733, IAEA, Vienna (1991)

[7] A A Tuccillo et al. Plasma Phys. Control. Fusion 47 (2005) B363

[8] N J Fisch, Rev. Mod. Phys. 59 (1987) 175

[9] R W Harvey et al. Proc. of the IAEA Tech. Committee Meeting on Advances in Simulation and Modeling of Thermonuclear Plasmas, Montreal, 1992 (IAEA, Vienna, 1993) 489

[10] A P Smirnov and R.W. Harvey, Bull. Am. Phys. Soc. 40 (1995) 1837

[11] Y Peysson and J Decker 34th EPS Conference on Plasma Phys. Warsaw, CD-ROM file P4.164 (2007) http://epsppd.epfl.ch/Warsaw/start.htm

[12] Y. Peysson and J. Decker Proc. of the Theory of Fusion Plasmas: Joint VarennaLausanne International Workshop, 2008 (AIP Conference Proc. 1069, Theory of Fusion Plasmas, Editors X. Garbet, O. Sauter, E. Sindoni, 2008) 176 and http://proceedings.aip.org/proceedings/

[13] P T Bonoli et al. in Fusion Energy 2006 (Proc. 21st Int. Conf. Chengdu, 2006) (Vienna: IAEA) CD-ROM file IT/P1-2 and http://www-naweb.iaea.org/napc/physics/FEC/FEC2006/html/index.htm

[14] M Shimada et al. Progress in the ITER Physics Basis Chapter 1: Overview and summary 2007 Nucl. Fusion 47 S1

[15] M L Watkins et al. in Fusion Energy 2006 (Proc. 21st Int. Conf. Chengdu, 2006) (Vienna: IAEA) CD-ROM file OV/1-3 and http://www-naweb.iaea.org/napc/physics/FEC/FEC2006/html/index.htm [16] S Ide et al. in Fusion Energy 1998 (Proc. 17th Int. Conf. Yokohama, 1998) (Vienna: IAEA) CD-ROM file CD1/4 and http://www.iaea.org/programmes/ripc/physics/start.htm. [17] C E Kessel et al. Nucl. Fusion 47 (2007) 1274 
[18] A Polevoi et al. Nucl. Fusion 48 (2008) 015002

[19] J Garcia et al. Phys. Rev. Lett. 100 (2008) 255004

[20] V Basiuk et al. Nucl. Fusion 43 (2003) 822

[21] S H Kim et al. "Lower hybrid assisted plasma current ramp-up in ITER" accepted for publication in Plasma Phys. Control. Fusion (scheduled for May 2009)

[22] S C Jardin et al. J. Comp. Phys. 66 (1986) 481

[23] V Parail et al. "Integrated Modelling for ITER in EU" submitted to Nuclear Fusion (2009)

[24] C Kessel et al. "Development of ITER 15 MA ELMy H-mode Inductive Scenario" submitted to Nuclear Fusion (2009)

[25] J.R. Wilson et al. Fusion Energy 2008 (Proc. 22nd Int. Conf. Geneva, 2008) (Vienna: IAEA) CD-ROM file EX/P6-21 and http://www-naweb.iaea.org/napc/physics/FEC/FEC2008/html/index.htm [26] F C Jobes et al. Phys. Rev. Lett. 52 (1984) 1005

[27] F Kazarian et al. Proc. 25th Symposium on Fusion Technology (Rostock, 2008) P3-14

[28] Ph Bibet el al. Fusion Eng. Design 66-68 (2003) 525

[29] F. Mirizzi et al. Fusion Eng. Design, vol. 66- 68 (2003) 621

[30] Ph Bibet et al. Fusion Eng. Design 51-52 (2000) 741

[31] D Guilhem et al. Proc. 25th Symposium on Fusion Technology (Rostock, 2008) P3-16

[32] V Pericoli Ridolfini et al. Nucl. Fusion 45, 1085 (2005)

[33] Ph Bibet et al. $6^{\text {th }}$ International Workshop on Strong Microwaves in Plasmas 2005, Vol.

2, p. 554 (Ed. A.G. Litvak, Nizhny Novgorod 2006)

[34] E. Barbato and A. Saveliev, Plasma Phys. Contr. Fus. 46 (2004) 1283

[35] M Schneider et al. Proc. 33rd EPS Conference on Plasma Phys., Rome, CD-ROM file P1.118 (2006) and http://epsppd.epfl.ch/Roma/start.htm

[36] M Porkolab, Physics of Fluids 20 (1977) 2058

[37] D Van Houtte et al. Nucl. Fusion 44 (2004) L11

[38] S Itoh et al. Nucl. Fusion 39 (1999) 1257

[39] H Zushi et al. Nucl. Fusion 43 (2003) 1600

[40] Y Ikeda et al. in Plasma Physics and Controlled Nuclear Fusion Research 1994 (Proc. 15th Int. Conf. Seville, 1994), Vol. 1, p. 415, IAEA, Vienna (1995)

[41] O Naito et al. Journal of Nuclear Materials 220-222 (1995) 425 
[42] G Giruzzi et al. in Plasma Physics and Controlled Nuclear Fusion Research 1994 (Proc. 15th Int. Conf. Seville, 1994), Vol. 2, p. 197, IAEA, Vienna (1995)

[43] A Ekedahl et al. Nucl. Fusion 45 (2005) 351

[44] K Rantamäki, A. Ekedahl et al. $17^{\text {th }}$ Topical Conf. on RF Power in Plasmas, Clearwater, FL (2007). AIP Conf. Proceedings 933 (2007) 261

[45] L Colas et al. Plasma Physics and Controlled Fusion 49 (2007) B35 